\title{
Breaking silence: a survey of barriers to goals of care discussions from the perspective of oncology practitioners
}

\author{
Katrina Lynn Piggott ${ }^{1 *}$, Ameen Patel ${ }^{2}$, Arthur Wong ${ }^{2}$, Leslie Martin², Alexandra Patel ${ }^{3}$, Matthew Patel ${ }^{4}$, Yudong Liu ${ }^{5}$,
} Sukhbinder Dhesy-Thind ${ }^{6}$ and John J. You ${ }^{2,7}$

\begin{abstract}
Background: Cancer is the leading cause of death in the developed world, and yet healthcare practitioners infrequently discuss goals of care $(\mathrm{GoC})$ with hospitalized cancer patients. We sought to identify barriers to GoC discussions from the perspectives of staff oncologists, oncology residents, and oncology nurses.

Methods: This was a single center survey of staff oncologists, oncology residents, and inpatient oncology nurses. Barriers to GoC discussions were assessed on a 7-point Likert scale ( 1 = extremely unimportant; $7=$ extremely important).

Results: Between July 2013 and May 2014, of 185 eligible oncology clinicians, 30 staff oncologists, 10 oncology residents, and 28 oncology nurses returned surveys (response rate of 37\%). The most important barriers to GoC discussions were patient and family factors. They included family members' difficulty accepting poor prognoses (mean score 5.9, 95\% Cl [5. $7,6.2]$ ), lack of family agreement in the goals of care (mean score $5.8,95 \% \mathrm{Cl}[5.5,6.1])$, difficulty understanding the limitations of life-sustaining treatments (mean score $5.8,95 \% \mathrm{Cl}[5.6,6.1]$ ), lack of patients' capacity to make goals of care decisions (mean score 5.7, 95\% Cl [5.5, 6.0]), and language barriers (mean score 5.7, 95\% Cl [5.4, 5.9]). Participants viewed system factors and healthcare provider factors as less important barriers.

Conclusions: Oncology practitioners perceive patient and family factors as the most limiting barriers to GoC discussions. Our findings underscore the need for oncology clinicians to be equipped with strong communication skills to help patients and families navigate GoC discussions.
\end{abstract}

Keywords: Goals of care discussions, End of life, Barriers, Cancer care

\section{Background}

Cancer is a leading cause of mortality in the developed world [1]. Most terminally-ill cancer patients prefer to die at home [2]. Despite this, approximately one third still die in hospital, and nearly $10 \%$ die in the intensive care unit (ICU) [3]. An estimated $30 \%$ of patients offered chemotherapy are in the last months of life, and this percentage is increasing each year, as are emergency room (ER) visits, hospitalizations, and admissions to the ICU [4-8]. Physicians often lack awareness of their patients' wishes to avoid resuscitation in hospital [9].

\footnotetext{
* Correspondence: katrina.piggott@mail.utoronto.ca

'Department of Geriatric Medicine, 30 Bond Street, Room 4-002, Shuter

Wing, Toronto, ON M5B 1W8, Canada

Full list of author information is available at the end of the article
}

Unwanted aggressive care at the end of life (EOL) is associated with increased healthcare costs, worse quality of life, and a worse death [10].

Decision-making about goals of care $(\mathrm{GoC})$ has been defined as a communication process that occurs between clinicians and a patient to establish a care plan, and includes decisions about the use or non-use of life-sustaining treatments [11]. Less than a third of patients with advanced cancer have had a GoC discussion with a member of care team $[10,12]$. As a result, patients may be subject to unwanted aggressive treatments near the end of life. Cancer patients who die in hospital experience more pain, anxiety, and physical and emotional distress compared to those who die at home with hospice services [13, 14]. Furthermore, when patients die in the ICU or in hospital, family members and caregivers are at higher risk for both

(c) The Author(s). 2019 Open Access This article is distributed under the terms of the Creative Commons Attribution 4.0 International License (http://creativecommons.org/licenses/by/4.0/), which permits unrestricted use, distribution, and reproduction in any medium, provided you give appropriate credit to the original author(s) and the source, provide a link to the Creative Commons license, and indicate if changes were made. The Creative Commons Public Domain Dedication waiver (http://creativecommons.org/publicdomain/zero/1.0/) applies to the data made available in this article, unless otherwise stated. 
post-traumatic stress disorder and prolonged grief disorder $[15,16]$. In contrast, patients who have a more accurate understanding of their prognosis are more likely to decline aggressive interventions and resuscitation at the EOL [15]. $\mathrm{GoC}$ discussions between patients and physicians are associated with fewer life-sustaining interventions, fewer ICU admissions, better patient outcomes [14], and lower healthcare costs [17].

Hospitalization of a patient with advanced cancer marks an important inflection point in their illness trajectory and presents an important opportunity to clarify GoC. While the importance of support and communication around end-of-life decision-making in advanced cancer has been recognized [18], relatively few studies have identified the relative importance of barriers to $\mathrm{GoC}$ discussions in the oncology population. Previous studies have attempted to explore barriers experienced by physicians such as personal discomfort with death and dying $[19,20]$. An improved understanding of the barriers to $\mathrm{GoC}$ discussions with hospitalized patients who have advanced cancer will inform the design of future strategies aimed at improving both the quantity and quality of $\mathrm{GoC}$ discussions in this patient population. The aim of this study was to identify barriers to $\mathrm{GoC}$ discussions with hospitalized patients who have advanced cancer, as perceived by oncology clinicians.

\section{Methods}

We conducted a cross-sectional survey on all oncology wards of the Juravinski Hospital and Cancer Centre in Hamilton, Ontario, between July 2013 and May 2014. We defined oncology inpatient wards as a unit where staff oncologists, oncology residents, and nurses provided care for admitted patients with cancer. The Hamilton Integrated Research Ethics Board approved the study. Participants gave implicit informed consent through completion of the self-administered questionnaire in response to an invitation to participate voluntarily.

We surveyed oncology clinicians according to the following inclusion criteria: 1) staff oncologists providing care to cancer inpatients, 2) residents enrolled as a subspecialty trainee in the hematology, radiation, and medical oncology programs at McMaster University, and 3) nurses (registered nurses, advanced practice nurses, licensed practical nurses, or registered practical nurses) employed full time, or part time, on the oncology wards.

Physician-specific (staff oncologist or oncology resident) and nurse-specific versions of the questionnaire were created to capture items specific to each professional group. The questionnaire used in this study was adapted from a questionnaire used previously to quantify barriers to goals of care discussions, as perceived by clinicians, with seriously ill hospitalized patients on medical teaching units [21]. This original questionnaire was drafted by the authors, presented to a national focus group, revised by front-line clinicians, and then pilot-tested with physicians and nurses on a medical teaching unit (MTU) in Hamilton, Ontario, Canada. To adapt the survey for this study, oncologists provided clinical expertise and feedback on the content and structure of the questionnaire, including the hypothetical patient vignettes. We pilot-tested the initial adapted version with the study investigators and made revisions to improve clarity in a final version.

The final questionnaire was then distributed in a paper-based format to oncology clinicians and electronic reminders were given to non-responders [22]. The preamble to the questionnaire presented the definition of goals-of-care discussions to be used for this study: "We define communication and decision-making about goals of care as a conversation in which, ideally, a patient or family member and the healthcare team establish the goals of treatment (e.g., cure, prolongation of life, comfort) and agree upon the types of life sustaining technology that will (or will not) be used to achieve those goals (e.g., CPR, mechanical ventilation, dialysis, intensive care unit admission, feeding tubes, or intravenous hydration)" [11]. Each questionnaire contained a clinical vignette (Fig. 1) that was tailored to each subspecialty of oncology (medical, hematology, radiation). Barriers to $\mathrm{GoC}$ discussions were assessed on a 7-point Likert scale ( $1=$ extremely unimportant, 2 = very unimportant, $3=$ somewhat unimportant, $4=$ neither important nor unimportant, $5=$ somewhat important, $6=$ very important, $7=$ extremely important). Participants were then asked to rate their willingness to participate in different aspects of $\mathrm{GoC}$ discussions (initiate discussion, exchange information, act as a decision coach, make a final decision) on the same 7-point Likert scale. Finally, participants were asked to rate how acceptable they found it to have other healthcare professionals initiate and participate in these different aspects of GoC discussions using the same 7-point Likert Scale.

All statistical analyses were performed with the use of SPSS software. We summarized continuous data using means and categorical data using proportions. We report survey responses as means and 95\% confidence intervals.

\section{Results}

The overall response rate was $68 / 185$ (37\%); (30/51 [57\%] among staff oncologists, 10/26 [38\%] among oncology residents, and 28/108 [26\%] among oncology nurses). Figure 2 depicts the professional training of the study respondents, and the demographic characteristics of the study participants are shown in Table 1.

\section{Barriers to goals of care discussions as perceived by oncology clinicians}

Participants perceived patient and family member factors as the most important barriers to GoC discussions. These 


\begin{tabular}{|c|c|c|}
\hline $\begin{array}{l}\text { A } \\
\text { Hematology Oncology } \\
\text { Scenario: A } 70 \text { year old man is } \\
\text { admitted to the hematology } \\
\text { ward with progressive } \\
\text { multiple myeloma and } \\
\text { increasing bone pain. He was } \\
\text { diagnosed with multiple } \\
\text { myeloma } 8 \text { years ago and has } \\
\text { undergone two previous } \\
\text { autologous stem cell } \\
\text { transplants. He is currently on } \\
\text { a third line clinical trial drug } \\
\text { with refractory disease. It has } \\
\text { been difficult to control his } \\
\text { bone pain at home and he has } \\
\text { been admitted for } \\
\text { optimization of analgesia. You } \\
\text { are uncertain about the } \\
\text { patient's goals of care and } \\
\text { preferences regarding the use } \\
\text { (or non-use) of life sustaining } \\
\text { technology. }\end{array}$ & $\begin{array}{l}\text { B } \\
\text { Medical Oncology Scenario: A } \\
55 \text { year old woman with } \\
\text { advanced breast cancer, } \\
\text { currently on hormonal therapy, } \\
\text { is admitted to the oncology ward } \\
\text { under your care with shortness } \\
\text { of breath secondary to a newly } \\
\text { discovered malignant pleural } \\
\text { effusion. A pigtail catheter has } \\
\text { been inserted and her shortness } \\
\text { of breath has improved. } \\
\text { However, her performance } \\
\text { status remains poor due to her } \\
\text { disease burden. She is capable of } \\
\text { only minimal self care and is } \\
\text { confined to bed or a chair for } \\
\text { most of the day. You are } \\
\text { uncertain about the patient's } \\
\text { goals of care and preferences } \\
\text { regarding the use (or non-use) of } \\
\text { life sustaining technology. }\end{array}$ & $\begin{array}{l}\text { C } \\
\text { Radiation Oncology } \\
\text { Scenario: A } 65 \text { year old } \\
\text { gentleman with advanced non- } \\
\text { small cell lung cancer is } \\
\text { admitted to the radiation } \\
\text { oncology ward under your } \\
\text { care following presentation } \\
\text { with falls and confusion. } \\
\text { Imaging identified new brain } \\
\text { metastases. Consultation with } \\
\text { Neurosurgery has determined } \\
\text { he is not a candidate for } \\
\text { surgical intervention. You are } \\
\text { considering treatment with } \\
\text { whole brain radiation therapy. } \\
\text { All lines of chemotherapy have } \\
\text { been exhausted. You are } \\
\text { uncertain about the patient's } \\
\text { goals of care and preferences } \\
\text { regarding the use (or non-use) } \\
\text { of life sustaining technology. }\end{array}$ \\
\hline
\end{tabular}

Fig. 1 Clinical Vignettes. Clinical vignettes for clinicians in: (a) hematology oncology, (b) medical oncology, and (c) radiation oncology

included: family members' difficulty accepting a poor prognosis, lack of family agreement in the goals of care, difficulty understanding the limitations of life-sustaining treatments, lack of patients' capacity to make goals of care decisions, and language barriers. Study participants viewed system factors and healthcare provider factors as less important barriers. Among external and system factors, lack of time was perceived as one of the more important barriers. Figure 3 illustrates the perceived barriers rated in this study, and all mean scores are tabulated in Additional file 1.

\section{Perceptions of inter-professional roles in communication and decision making about goals of care}

Physicians and nurses together expressed a willingness to engage in $\mathrm{GoC}$ discussions, including initiating discussions with patients and family, exchanging important information such as diagnosis and prognosis, acting as a decision coach, and making a final decision together with the patient (Additional file 2).
Participants were agreeable to involving allied health professionals in certain aspects of $\mathrm{GoC}$ discussions. For initiating a discussion or acting as a decision coach, participants felt that it would be appropriate for many different members of the inter-professional team to be involved, including the admitting oncologist, resident, advanced practice nurse, social worker, or bedside nurse. In contrast, for exchanging pertinent information such as diagnosis or prognosis, or making a final decision together with the patient, study participants felt that the most acceptable individual was the admitting oncologist, followed by the resident, and then advanced practice nurse. Participants felt it was less acceptable for other allied health professionals such as physiotherapists, occupational therapists, registered dieticians, speech language pathologists or pharmacists to engage in these other aspects of GoC discussions (Fig. 4, Additional file 3).

\section{Discussion}

In this survey of staff oncologists, oncology residents, and nurses caring for patients with cancer at an academic

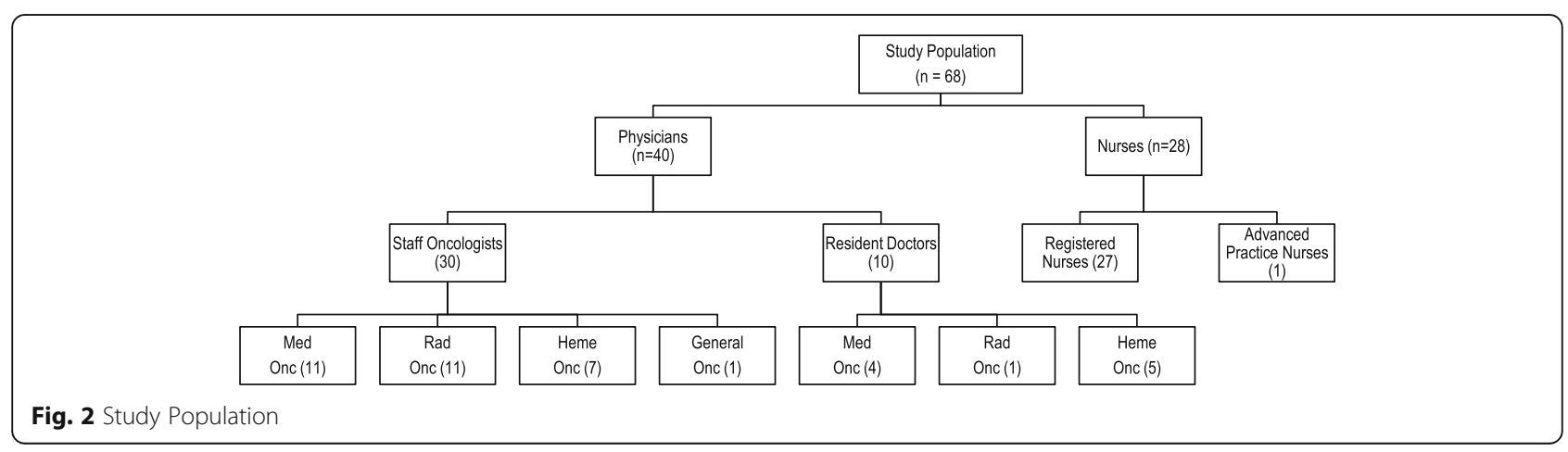


Table 1 Characteristics of Respondents

\begin{tabular}{ll}
\hline Nurses $(n=28)$ & \\
\hline Age (mean) & 40.2 \\
Male & $2(7 \%)$ \\
Female & $26(93 \%)$ \\
Years of practice (mean) & 12.0 \\
Staff Physicians ( $n=30)$ & \\
Age (mean) & 42 \\
Male & $21(70 \%)$ \\
Female & $9(30 \%)$ \\
Years of practice (mean) & 12.5 \\
Resident Physicians ( $n=10)$ & \\
Age (mean) & 31.4 \\
Male & $8(80 \%)$ \\
Female & $2(20 \%)$ \\
Weeks of inpatient subspecialty & 5.9 \\
oncology completed (mean) & \\
\hline
\end{tabular}

cancer centre, we found that oncology clinicians perceived patient and family factors as the most important barriers to $\mathrm{GoC}$ discussions, and that system and healthcare provider factors were viewed as less important. Study participants also expressed a willingness to engage in many aspects of $\mathrm{GoC}$ discussions, such as initiating discussions, exchanging critical information such as prognosis, and making a final decision. Study participants found it acceptable for many different professional groups, including social workers and nurses, to initiate GoC discussions and act as a decision coach.
Cancer patients are more likely to receive care consistent with their preferences when they have had a GoC discussion with their physician, and are more likely to opt for symptom-directed care when they recognize their illness is terminal [23]. While $\mathrm{GoC}$ discussions improve the dying experience for patients [24], this study adds to the literature demonstrating that patient and family factors are the biggest barriers to effective $\mathrm{GoC}$ discussions as perceived by clinicians [21]. Although study participants rated practitioner factors as less important barriers to $\mathrm{GoC}$, this has several interpretations and implications. First, it reflects that patients who have advanced cancer and their families may often find it difficult to confront a poor prognosis. As a result, oncology clinicians should anticipate that patients and families may find GoC conversations difficult or emotionally laden and be prepared to guide patients and families through these discussions. However patients who have cancer report that physicians are particularly inadequate in discussing emotional symptoms, life support preferences and hospice care, regardless of the patient's age or disease stage [25]. Indeed, other studies have found that oncology practitioners often lack communication skills training and have discomfort with difficult discussions that include mortality acknowledgement and the introduction of a palliative approach to care [26-29]. This suggests that oncology clinicians may benefit from further training and continuing professional development to enhance their communication skills in order to best support patients and their families in $\mathrm{GoC}$ conversations [30]. Patients facing serious illnesses prefer to actively participate in EOL care planning [31-34]. While patient factors are often rated as the most significant barriers to communication, with formal training, oncology

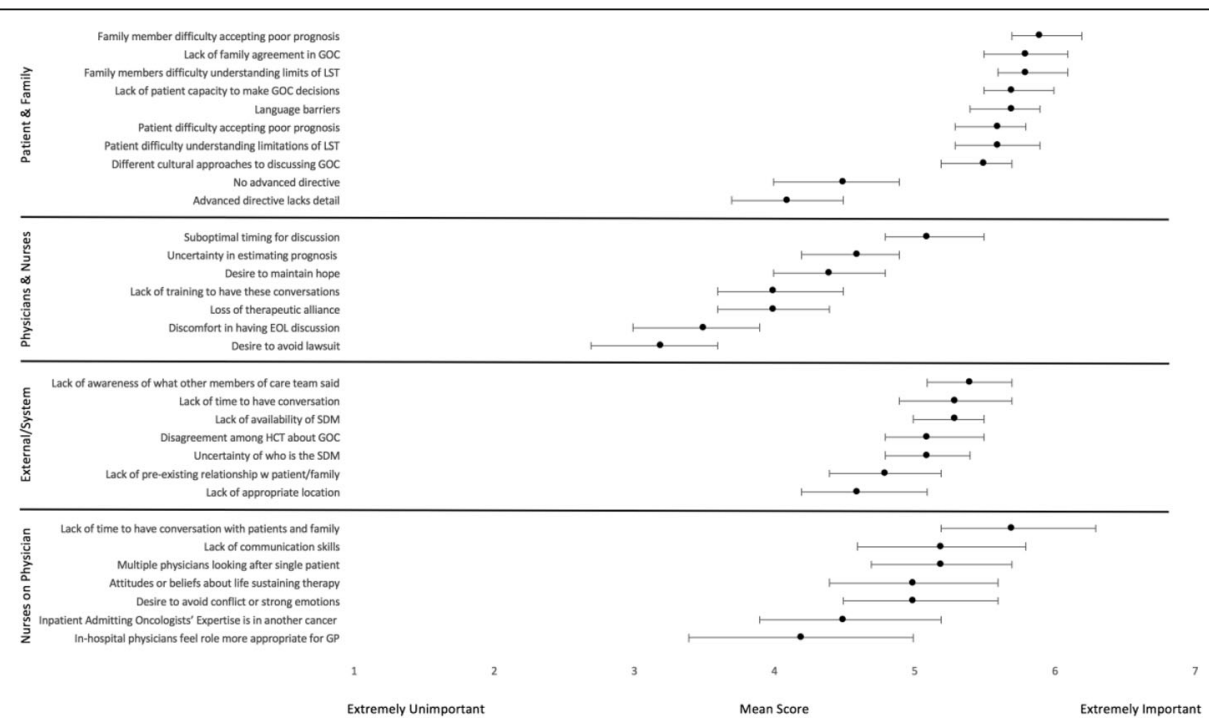

Fig. 3 Perceived Barriers to Goals of Care Discussions. Combined mean scores from physicians and nurses on a Likert scale, rating the perceived barriers related to patient and family, the role of physicians and nurses from their own perspective, system and external factors, and the role of physicians from nurses' perspective. The error bars denote $95 \%$ confidence intervals 


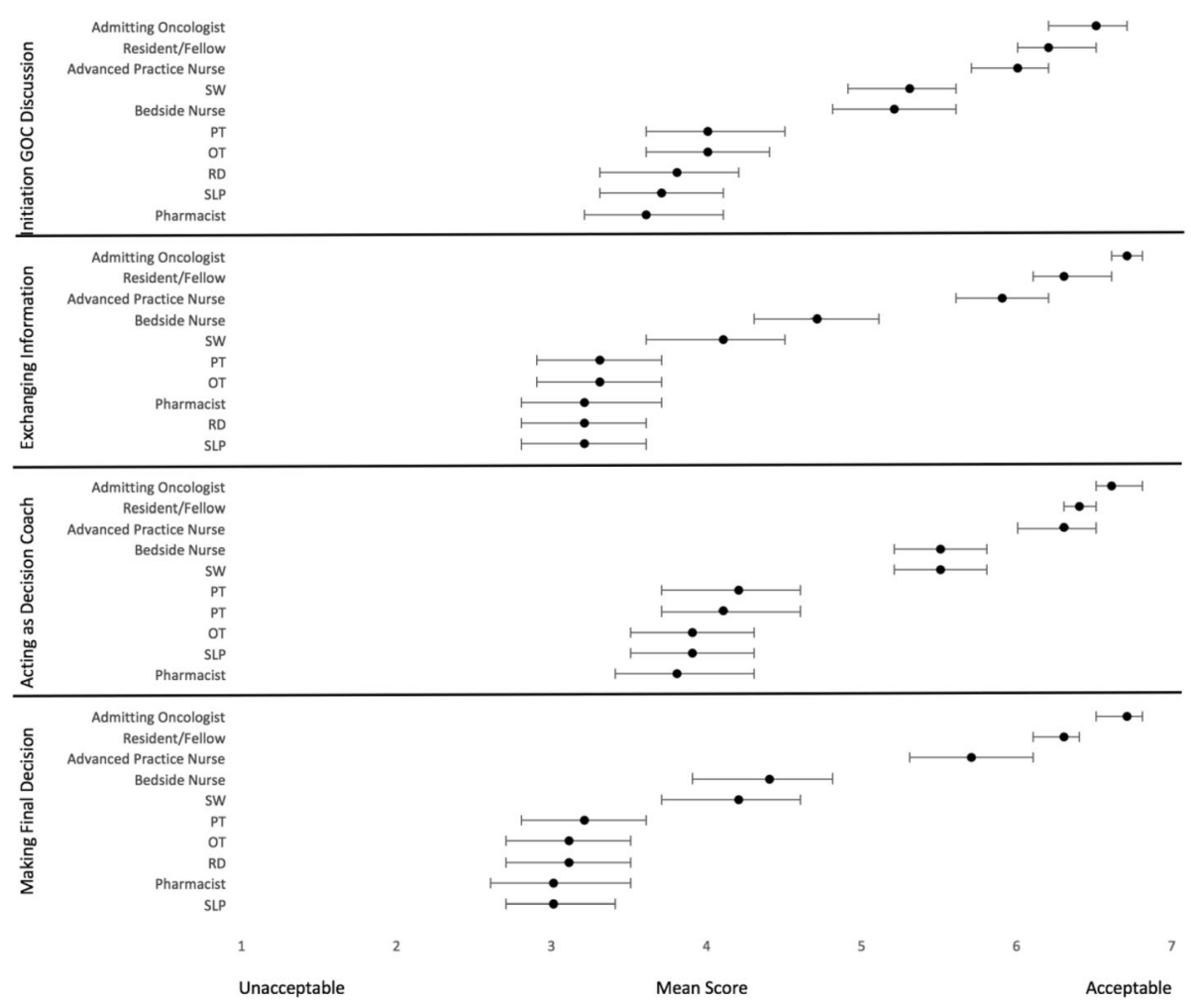

Fig. 4 Acceptability of Inter-Professional Healthcare Team Members to Engage in Goals of Care Discussions. Combined mean score from physicians and nurses on a Likert scale rating the acceptability of inter-professional healthcare team members in initiating GOC discussion, exchanging information, acting as decision coach, making final decision. The error bars denote $95 \%$ confidence intervals

clinicians can master communication skills that will empower them to guide patients with advanced cancer through frank discussions about their prognosis and preferences for care at the end of life, preferably early in the course of disease $[35,36]$. Formal training would also give clinicians an opportunity to learn and use validated tools for initiating these discussions [37] and develop an approach that recognizes the benefits of these conversations, while helping patients to discuss their values and preferences [19].

Despite many highly-rated barriers to GoC discussions, oncology physicians, residents and nurses described themselves as willing to engage in these important conversations. This likely reflects progressive awareness among providers that many cancer patients have not had GoC discussions, even at the time of admission to hospital, and of those who have, as many as half lack formal documentation of these conversations [9]. There is growing appreciation for both the importance and the timing of $\mathrm{GoC}$ discussions, as cancer patients who discuss their GoC with their healthcare team enter hospice care earlier, have fewer critical care admissions, a greater likelihood of dying outside the hospital, and a significantly improved quality of life [14, 38]. Finally, it likely reflects a rising awareness of advanced cancer patients wishing to avoid unwanted life support as a key element of quality end of life care [39].

The findings of this study also emphasized a lack of time as an important barrier, across all categories. Prioritizing protected time for important discussions is of great importance [40]. An acute admission to hospital marks an important change in disease trajectory, but only half of patients with advanced cancer who have documented EOL care discussions with their providers do so in the context of an emergency room visit or inpatient hospitalization [41]. Furthermore, acute care hospitals have performed poorly overall when evaluated on the quality of their end-of-life communication, as measured by validated quality indicators [42]. Ultimately, hospitalizations leave little time for discussion unless it is a priority, and patients may not have the same ability to recognize their hospitalization as a worsening of their prognosis. An admission to acute care often represents an important inflection point in a patient's illness trajectory and should serve as a potent reminder to oncology clinicians to open the lines of communication and to discuss or revisit goals of care with their patients.

To further support patients and families, many tools and decision aids for patients have been explored, with the intention of helping patients ask questions, understand difficult decisions, and ultimately receive care that 
is aligned with their values and goals [43]. Question prompt lists have assisted patients and their caregivers to ask questions about end-of-life issues without contributing anxiety or impairing satisfaction [44]. Video decision aids have significantly decreased the likelihood that patients will opt for CPR and resuscitation, and be more certain of their decision-making $[45,46]$. More significantly, decision aids have increased the likelihood that their choices ultimately reflect their own values [47]. While these tools are promising, the results of this study bring to light a myriad of barriers perceived by healthcare providers that need to be addressed. While decision aids may be helpful adjuncts, they cannot personalize disclosure of prognosis, and do not take the place of an honest, nuanced, and compassionate interaction between the patient and the clinicians caring for them.

Another implication of this study is the opportunity to include allied health professionals in GoC discussions. Second to physicians, study participants felt advanced practice nurses were most appropriate to engage in $\mathrm{GoC}$ discussions. Similarly, bedside nurses and social workers were felt to be acceptable individuals to specifically initiate discussions and act as a decision coach. This is supported by literature, where both nurses and social workers are significantly involved in end of life care, including a willingness to participate in $\mathrm{GoC}$ decision-making [48]. Social workers can be integral in information giving and education, as well as helping patients reach final decisions [49]. There is also great initiative and willingness on the part of other allied health members to play an active role [50-52]. These skilled individuals have a unique understanding of a patients' health status, and concurrently can establish a unique rapport. This study's findings suggest that there is an opportunity to adopt a more interprofessional approach to having conversations about a patient's values, preferences, and goals of care.

There are several limitations to this study. It was conducted at a single academic cancer centre, and the respondents, on average, were relatively young or, in the case of oncology residents, had relatively little experience in subspecialty oncology settings. In addition, to the extent that non-responders held different views than our study participants, the $37 \%$ response rate in our study may limit the generalizability of our findings. However, our findings were remarkably similar to findings from a multi-center survey of practitioners (response rate 78\%) that we conducted on hospital medical wards [21]. Therefore, our study confirms that the findings of our earlier study are generalizable to the oncology setting, suggesting that barriers to goals-ofcare discussions during serious illness may be similar regardless of the specific disease state and that disease-agnostic interventions to improve communication during serious illness may be useful. Finally, it is possible that respondents might have been influenced by infrequent but very memorable interactions with advanced cancer patients or their families. Certain challenging interactions are subject to recall bias and as a result, respondents may have placed undue weight on patient and family factors.

\section{Conclusions}

Oncology clinicians perceive patient and family factors as the most important barriers to $\mathrm{GoC}$ discussions. This insight forms an important platform for future interventions. Our findings highlight the potential for high levels of anxiety or even denial faced by patients with advanced cancer. This underscores the need for oncology clinicians to be equipped with strong communication skills to help patients and their families to navigate $\mathrm{GoC}$ decisions. Making time for these crucial conversations and planning to have them throughout the course of illness is imperative. $\mathrm{GoC}$ discussions should be initiated by physicians and nurses who have received focused training in this regard, and the discussion would be made richer with the help of skilled allied health professionals.

\section{Additional files}

Additional file 1: Mean scores from physicians and nurses on a Likert scale, rating barriers related to patient and family factors, the role of physicians and nurses from their own perspective, system and external factors, and the role of physicians from nurses' perspective. (DOCX $19 \mathrm{~kb}$ )

Additional file 2: Mean Likert scores, physicians and nurses rating their own willingness to engage in goals of care discussions. (DOCX $50 \mathrm{~kb}$ )

Additional file 3: Mean scores from physicians and nurses on a Likert scale, rating their perceptions of inter-professional roles in communicating and decision-making around goals of care. (DOCX $91 \mathrm{~kb}$ )

\section{Abbreviations}

EOL: End of Life; ER: Emergency Room; GoC: Goals of Care; ICU: Intensive Care Unit; MTU: Medical Teaching Unit

\section{Acknowledgements}

The authors would like to thank Parveen Wasi, Lindsay Melvin, lan Mazzetti, Jessica Singh, Jennifer Goy and Sharon Hendershott for their contribution to the development and distribution of this study's questionnaire.

Presented: The study was reported previously as a poster presentation at the Canadian Society of Internal Medicine Conference in 2015.

\section{Funding}

This study did not receive private or public funding.

Availability of data and materials

The study database is available from the authors upon request.

\section{Authors' contributions}

All authors have read and approved the manuscript and made the following contributions: KLP: Data analysis, manuscript preparation and critical review of the manuscript. AP (Ameen Patel): conception of the study, critical review of the manuscript. AW: data analysis, critical review of the manuscript. LM: data analysis, critical review of the manuscript. AP (Alexandra Patel): data collection, critical review of the manuscript. MP: data collection, critical review of the manuscript. YL: conception of the study, critical review of the manuscript. BD: conception of the study, critical review of the manuscript. JY: conception of the study, data collection, manuscript preparation and approval. 


\section{Ethics approval and consent to participate}

This study has full approval from the Hamilton Integrated Research Ethics Board (study reference \#11-631). Participant consent was implied by completion of the study questionnaire.

\section{Consent for publication}

Not applicable, no individual participant's data is reported.

\section{Competing interests}

All authors have read and approved this manuscript, and declare that this is a work of original intellectual effort. They have no conflicts of interest to disclose. The manuscript is not under consideration for publication by any other journal.

\section{Publisher's Note}

Springer Nature remains neutral with regard to jurisdictional claims in published maps and institutional affiliations.

\section{Author details}

'Department of Geriatric Medicine, 30 Bond Street, Room 4-002, Shuter Wing, Toronto, ON M5B 1W8, Canada. ${ }^{2}$ Department of Medicine, McMaster University, 1200 Main Street West, Hamilton, ON L8N 3Z5, Canada. ${ }^{3}$ Department of Occupational Science and Occupational Therapy, The University of Toronto, 500 University Avenue, Toronto, ON M5G 1V7, Canada. ${ }^{4}$ Royal College of Surgeons in Ireland, 123 St Stephen's Green, Dublin 2, Ireland. ${ }^{5}$ Schulich School of Dentistry, University of Western Ontario, 1151 Richmond St, London, ON N6A 5C1, Canada. ${ }^{6}$ Department of Oncology, McMaster University, 699 Concession St, Hamilton, ON L8V 5C2, Canada. ${ }^{7}$ Department of Health Research Methods, Evidence, and Impact, McMaster University, 1280 Main St West, Hamilton, ON L8S 4K1, Canada.

Received: 4 August 2018 Accepted: 30 January 2019

Published online: 08 February 2019

\section{References}

1. Canadian Cancer Society. Right to Care: Palliative Care for All Canadians, 2016 Report. Accessed 19 May 2016. https://www.cancer.ca/ /media/cancer.ca/CW/ get\%20involved/take\%20action/Palliative-care-report-2016-EN.pdf?la=en

2. Bruera E, Russell N, Sweeney $\mathrm{C}$, et al. Place of death and its predictors for local patients registered at a comprehensive cancer center. J Clin Oncol. 2002;20:2127-33.

3. Angus DC, Barnato $A E$, Linde-Zwirble $W T$, et al. Use of intensive care at the end of life in the United States. Crit Care Med. 2004;32:638-43.

4. Earle CC, Landrum MB, Souza JM, et al. Aggressiveness of cancer care near the end of life: is it a quality-of-care issue? J Clin Oncol. 2008;26:3860-6.

5. Emanuel EJ, Young-Xu Y, Levinsky NG, et al. Chemotherapy use among Medicare beneficiaries at the end of life. Ann Intern Med. 2003:138:639-43.

6. Temel JS, McCanon J, Greer JA, et al. Aggressiveness of care in a prospective cohort of patients with advanced NSCLC. Cancer. 2008;113:826-33.

7. Sharma G, Freeman J, Zhang D, et al. Trends in end-of-life ICU use among older adults with advanced lung cancer. Chest. 2008;133:72-8.

8. Earle C, Neville B, et al. Trends in the aggressiveness of Cancer care near the end of life. J Clin Oncol. 2004;24(2):315-21.

9. The SUPPORT Principal Investigators. A controlled trial to improve Care for Seriously ill Hospitalized Patients: the study to understand prognoses and preferences for outcomes and risks of treatments (SUPPORT) - the SUPPORT principal Investigators. JAMA. 1995;274:1591-8.

10. Zhang B, Wright A, et al. Health care costs in the last week of life - associations with end-of-life conversations. Arch Intern Med. 2009;169(5):480-8.

11. Sinuff T, Dodek P, You JJ, et al. Improving end-of-life communication and decision making: the development of a conceptual framework and quality indicators. J Pain Symptom Manag. 2015;49(6):107080. https://doi.org/10. 1016/j.jpainsymman.2014.12.007 Epub 2015 Jan 24. PubMed PMID: 25623923.

12. Huskamp HA, Keating NL, Malin JL, et al. Discussions with physicians about hospice among patients with metastatic lung cancer. Arch Intern Med. 2009:169:954-62 19.

13. Nelson JE, Meier DE, Oei EJ, et al. Self reported symptom experience of critically ill cancer patients receiving intensive care. Crit Care Med. 2001; 29(2):277-82.
14. Wright A, Keating N, et al. Place of death: correlations with quality of life of patients with Cancer and predictors of bereaved caregivers' mental health. J Clin Oncol. 2010;28(29):4457-64.

15. Wright AA, Zhang B, Ray A, et al. Associations between end-of-life discussions, patients' mental health, medical care near death, and caregiver bereavement adjustment. JAMA. 2008;300:1665-73.

16. Teno JM, Clarridge BR, Casey V, et al. Family perspectives on end-of-life care at the last place of care. JAMA. 2004;291:88-93.

17. Fries JF, Koop CE, Beadle CE, et al. Reducing health care costs by reducing the need and demand for medical services. N Engl J Med. 1993;329(5):321-5.

18. The American Society of Clinical Oncology (ASCO). Cancer care during the last phase of life. J Clin Oncol. 1998;16:1986-96.

19. Granek L, Krzyzanowska M, et al. Oncologists' strategies and barriers to effective communication about the end of life. J Oncol Pract. 2013;9:e129-35.

20. Mori M, Shimizu C, Ogawa A, et al. A National Survey to systematically identify factors associated with Oncologists' attitudes toward end-of-life discussions: what determines timing of end-of-life discussions? Oncologist. 2015;20(11):1304-11.

21. You J, Downar J, Fowler R, et al. Barriers to goals of care discussions with seriously ill hospitalized patients and their families: a multicenter survey of clinicians. JAMA Intern Med. 2015:175(4):549-56.

22. Dillman DA. Mail and Internet surveys: the tailored design method. New York, NY: Wiley; 2000.

23. Mack JW, Weeks JC, Wright AA, et al. End-of-life discussions, goal attainment, and distress at the end of life: predictors and outcomes of receipt of care consistent with preferences. J Clin Oncol. 2010;28:1203-8.

24. Lorenz KA, Lynn J, Dy SM, et al. Evidence for improving palliative care at the end of life: a systematic review. Ann Intern Med. 2008;148:147-59.

25. Nelson JE, Gay EB, Berman AR, et al. Patients rate physician communication about lung cancer. Cancer. 2011;117:5212-20.

26. Trice ED, Prigerson HG. Communication in end-stage cancer: review of the literature and future research. J Health Commun. 2009:14(Suppl 1):95-108.

27. Miyashita M, Sanjo M, Morita T, et al. Barriers to providing palliative care and priorities for future actions to advance palliative care in Japan: a nationwide expert opinion survey. J Palliat Med. 2007;10(2):390-9.

28. Feeg VD, Elebiary $H$. Exploratory study on end-of-life issues: barriers to palliative care and advance directives. Am J Hosp Palliat Care. 2005;22(2): 119-24.

29. Love A, Liversage LM. Barriers to accessing palliative care: a review of the literature. Progress in Palliative Care. 2014:22:9-19.

30. Bernacki RE, Block SD. American College of Physicians High Value Care Task Force. Communication about serious illness care goals: a review and synthesis of best practices. JAMA Intern Med. 2014;174(12):1994-2003. https://doi.org/10.1001/jamainternmed.2014.5271 Review. PubMed PMID: 25330167.

31. Parker SM, Clayton JM, Hancock K, et al. A systematic review of prognostic/ end-of-life communication with adults in the advanced stages of a lifelimiting illness: patient/caregiver preferences for the content, style, and timing of information. J Pain Symptom Manag. 2007:34:81-93.

32. Steinhauser KE, Christakis NA, Clipp EC, et al. Preparing for the end of life: Preferences of patients, families, physicians, and other care providers. J Pain Symptom Manage. 2001;22:727-37.

33. Steinhauser KE, Christakis NA, Clipp EC, et al. Factors considered important at the end of life by patients, family, physicians, and other care providers. JAMA. 2000;284:2476-82.

34. Steinhauser KE, Clipp EC, McNeilly M, et al. In search of a good death: observations of patients, families, and providers. Ann Intern Med. 2000;132:825-32.

35. Yun YH, Lee CG, Kim SY, et al. The attitudes of cancer patients and their families toward the disclosure of terminal illness. J Clin Oncol. 2004:22:307-14.

36. Hagerty RG, Butow PN, Ellis PA, et al. Cancer patient preferences for communication of prognosis in the metastatic setting. J Clin Oncol. 2004;22: $1721-30$.

37. Baile WF, Buckman R, Lenzi R, et al. SPIKES - a six-step protocol for delivering bad news: application to the patient with cancer. Oncologist. 2000;5:302-11.

38. Detering $K M$, Hancock AD, Reade MC, et al. The impact of advance care planning on end of life care in elderly patients: randomized controlled trial. BMJ. 2010;340:C1345.

39. Heyland DK, Dodek P, Rocker G, et al. Canadian Researchers' end-of-life network (CARENET). What matters most in end-of-life care: perceptions of seriously ill patients and their family members. CMAJ. 2006;174:627-33. 
40. Mack JW, Cronin A, Keating NL, et al. Associations between end-of-life discussion characteristics and care received near death: a prospective cohort study. J Clin Oncol. 2012;30:4387-95.

41. Mack JW, Cronin A, Taback N, et al. End-of-life care discussions among patients with advanced cancer: a cohort study. Ann Intern Med. 2012;156:204-10.

42. Heyland DK, Dodek P, You J, et al. Validation of quality indicators for end-of-life communication: results of a multicentre survey. CMAJ. 2017;189(30):E980-9.

43. Elwyn $G$, Frosch D, Volandes $A E$, et al. Investing in deliberation: a definition and classification of decision support interventions for people facing difficult health decisions. Med Decis Mak. 2010;30:701-11.

44. Clayton JM, Butow PN, Tattersall MH, et al. Randomized controlled trial of a prompt list to help advanced cancer patients and their caregivers to ask questions about prognosis and end-of-life care. J Clin Oncol. 2007;25:715-23.

45. Volandes AE, Paasche-Orlow MK, Mitchell SL, et al. Randomized controlled trial of a video decision support tool for cardiopulmonary resuscitation decision making in advanced cancer. J Clin Oncol. 2013;31:380-6.

46. El-Jawahri A, Podgurski LM, Eichler AF, et al. Use of video to facilitate endof-life discussions with patients with cancer: a randomized controlled trial. J Clin Oncol. 2010;28:305-10.

47. Stacey D, Bennett CL, Barry MJ, et al. Decision aids for people facing health treatment or screening decisions. Cochrane Database Syst Rev. 2011;10: CD001431.

48. Werner P, Carmel S, Ziedenberg H. Nurses' and social workers' attitudes and beliefs about and involvement in life-sustaining treatment decisions. Health Soc Work. 2004;29(1):27-35.

49. Heyman JC, Gutheil IA. Social work involvement in end of life planning. J Gerontol Soc Work. 2006;47(3-4):47-61.

50. Meintzer, J., et al. The Role of Speech-Language Pathologists, Audiologists and Communication Health Assistants in End-of-Life Care. 2016; Available from: http://www.sac-oac.ca/sites/default/files/resources/end-of-life_ position-statement_en.pdf. Accessed 17 Feb 2017.

51. The Canadian Association of Occupational Therapists. CAOT position statement: occupational therapy and end-of-life care. Occupational Therapy Now. 2008;10(6):23-5.

52. Canadian Physiotherapy Association, C.P. Position Statement Primary Health Care. November, 2006; Available from: https://physiotherapy.ca/sites/default/ files/positionstatements/primary-health-care_en.pdf. Accessed 24 Feb 2017.

Ready to submit your research? Choose BMC and benefit from:

- fast, convenient online submission

- thorough peer review by experienced researchers in your field

- rapid publication on acceptance

- support for research data, including large and complex data types

- gold Open Access which fosters wider collaboration and increased citations

- maximum visibility for your research: over $100 \mathrm{M}$ website views per year

At $\mathrm{BMC}$, research is always in progress.

Learn more biomedcentral.com/submissions 